\title{
A MATERIALIDADE APLICADA PARA A DIVULGAÇÃO DE INFORMAÇÕES NAS NOTAS EXPLICATIVAS
}

\section{THE APPLIED MATERIALITY FOR DISCLOSURE OF INFORMATION IN THE NOTES TO THE FINANCIAL STATEMENTS}

\section{Recebimento: 09/10/2017- Aceite: 20/11/2017- Publicação: 23/12/2017 Processo de Avaliação: Double Blind Review}

Paulo Bekmessian Pinheiro ${ }^{1}$

Mestre em Ciências Contábeis e Atuariais pela Pontifícia Universidade Católica de São Paulo PUC-SP

pbpinh@yahoo.com.br

Sérgio de Iudícibus

Professor Doutor do Mestrado da Pontifícia Universidade Católica de São Paulo (PUC-SP)

Professor Emérito pela Faculdade de Economia e Administração da Universidade de São

Paulo (FEA/USP)

siudicibus@osite.com.br

Bruno Meirelles Salotti

Professor Doutor do Departamento de Contabilidade e Atuária da Faculdade de Economia e Administração da Universidade de São Paulo - FEA/USP

brunofea@usp.br

Nome Napoleão Verardi Galegale

Professor Doutor do Mestrado do Centro Paula Souza e da Pontifícia Universidade Católica de São Paulo (PUC-SP)

nvg@galegale.com.br

\section{RESUMO}

Esta pesquisa investigou como o conceito de materialidade pode ser aplicável para as informações divulgadas em notas explicativas. O trabalho justifica-se por fornecer fundamentos para a elaboração de critérios sobre materialidade para serem aplicados em pequenas, médias e grandes empresas, a fim de reduzir a um mínimo as áreas de inconsistência. Após concluído que a materialidade pode ser utilizada como "ferramenta" para se decidir qual é a informação adequada a ser divulgada em notas explicativas, demonstrou-se a aplicação do conceito para uma amostra intencional composta pelas Companhias Abertas do segmento de transportes rodoviário da BM\&FBOVESPA: JSL S.A. ("JSL") e Tegma Gestão Logística S.A. ("Tegma"). Os resultados demonstram ser possível aplicar o conceito de materialidade às notas explicativas e as análises indicam que entre $33 \%$ e $27 \%$ das informações divulgadas nas notas explicativas das Demonstrações Financeiras da JSL e Tegma poderiam ter sido excluídas com base na materialidade estabelecida para as respectivas Companhias.

\footnotetext{
${ }^{1}$ Autor para correspondência: Pontifícia Universidade Católica de São Paulo - PUCSP- R.: Monte Alegre, 984- Perdizes- São PauloSP- Brasil CEP05014-901.
} 
PALAVRAS-CHAVE: materialidade; divulgação; notas explicativas.

ABSTRACThis research investigated how the materiality concept may be applied to the information disclosed in the notes to the Financial Statements. The study justifies itself to provide basis for the calculation of materiality to be applied on small, medium and large entities, in order to reduce to a minimum areas of inconsistency. After concluding that materiality can be used as a "tool" to decide which information should be disclosed in the notes to the Financial Statement, the study applies the materiality concept to an intentional sample, consisting on Public Companies from the Trucking Corporate Governance of the BM\&FBOVESPA: JSL S.A. ("JSL") and Tegma Gestão e Logistica S.A. ("Tegma"). The results show that it is possible to use the materiality concept to the notes and the analyses indicate that between $33 \%$ and $27 \%$ of the information disclosed in the notes to the Financial Statements of JSL and Tegma could have been excluded based on the materiality calculated for the respective Companies.

KEY WORDS: materiality; disclosure; notes to the Financial Statements.

\section{INTRODUÇÃO}

A informação transmitida pela contabilidade já é preocupação de muitos estudos sobre o tema há alguns anos. O IBRACON (1987), por exemplo, emitiu a Estrutura Conceitual Básica da Contabilidade em que definiu como objetivo da contabilidade prover seus usuários de informações de natureza econômica, financeira, física e de produtividade da entidade. A partir dessa ideia, uma forma prática de verificar se a contabilidade está alcançando o seu objetivo é determinar o grau de utilização das demonstrações contábeis por parte dos usuários. $O$ fato de haver uma menor utilização dos demonstrativos pode indicar a ocorrência de falhas de comunicação e evidenciação decorrentes de linguagem inadequada utilizada nas demonstrações contábeis.

A SEC (2011), também demonstrou atenção sobre o assunto após examinar os relatórios contábeis de 183 firmas de diversos países que adotaram IFRS observando que as notas explicativas não continham informações divulgadas adequadamente que permitissem ao usuário ter uma visão clara sobre as políticas contábeis utilizadas para elaboração das demonstrações financeiras.

O estudo mais aprofundado sobre as divulgações em notas explicativas, chamado de Towards a Disclosure Framework for the Notes, foi publicado para consulta em julho de 2012 pelo EFRAG - European Financial Reporting Advisory Group. O principal objetivo deste trabalho foi buscar uma forma de padronização das publicações em notas explicativas, motivado pelo empobrecimento observado nas divulgações das demonstrações financeiras analisadas.

Segundo o EFRAG (2012), as informações incluídas nas notas explicativas ficaram deterioradas pelos seguintes motivos: estas se transformaram em um caminho para se compensarem as deficiências de reconhecimento e mensuração; aumentou-se o nível de complexidade das transações e eventos econômicos; houve uma dificuldade de se aplicar o conceito de materialidade para as informações divulgadas nas notas explicativas; utilizaram-se

Revista ENIAC Pesquisa, Guarulhos (SP), V.6, n.2, jun.- dez. 2017 
"checklists" de divulgação como medida de segurança; e ocorreram pressões de tempo para a emissão do relatório final.

Como consequência desses motivos citados pelo EFRAG (2012), a leitura das notas explicativas torna-se cada vez mais complexa, pois elas deixam ser apenas informações suplementares das demonstrações primárias do relatório contábil e de fácil compreensão.

O Brasil não está alheio a esse movimento mundial e busca um meio para se divulgarem nas demonstrações contábeis apenas informações que realmente interessem aos usuários para os orientarem nas suas decisões sobre uma entidade específica. Dessa forma, o CPC, em 11 de novembro de 2014, emitiu a Orientação Técnica OCPC 07, cujo título é Evidenciação na Divulgação dos Relatórios Contábil-Financeiros de Propósito Geral, e o objetivo é abordar os requisitos básicos de elaboração e evidenciação a serem observados na divulgação dos relatórios contábil-financeiros tratando, especificamente, da evidenciação nas notas explicativas.

Mesmo com esse passo importante dado pelo CPC para esclarecer quais são as informações que devem ser divulgadas em notas explicativas, ainda existe uma dúvida sobre como avaliar a materialidade da informação a ser divulgada. Esta questão está pendente por não existir um critério objetivo para se determinar o que é material a ser apresentado; ao contrário, a materialidade é lançada ao julgamento dos preparadores das demonstrações contábeis.

Acredita-se que uma das formas de aperfeiçoar a divulgação em nota explicativa é definir critérios objetivos para utilização e aplicação da materialidade.

A partir da premissa de Most (1977) de que não existe algo como a materialidade, pois ela é simplesmente um aspecto da relevância, havendo, de fato apenas itens materiais, pode-se relacionar a materialidade a uma característica mensurável do objeto contábil, possibilitando a sua quantificação e, consequentemente, sua aplicação para elaboração de demonstrações financeiras livres de informações irrelevantes.

Essa argumentação é sustentada pelos critérios que atualmente existem e são utilizados, principalmente por auditores independentes, para se determinar a materialidade.

Sendo assim, o objetivo desse estudo é analisar a aplicação de um conceito de materialidade às evidenciações de notas explicativas de Companhias Abertas e verificar se as companhias listadas do segmento de transporte rodoviário do Bovespa divulgam apenas informações materiais em suas notas explicativas.

Esse estudo é baseado na seguinte questão de pesquisa: como o conceito de materialidade pode ser aplicado para informações em notas explicativas?

Com a definição do problema de pesquisa, as prováveis respostas para essa questão, em forma de hipóteses, são:

H1. Existe um índice de materialidade que permite ao preparador identificar quais são as informações úteis para divulgação em notas explicativas; e 
H2. As Companhias Abertas do segmento de transporte rodoviário do BM\&FBOVESPA divulgam apenas informações materiais nas notas explicativas, baseando-se, exclusivamente, nos critérios desenvolvidos nessa pesquisa.

De maneira geral, esse trabalho possui as subsequentes implicações teóricas e práticas:

- Do ponto de vista teórico, contribui-se para o enriquecimento da teoria da contabilidade, uma vez que a abordagem da pesquisa busca compreender o significado de materialidade profundamente, bem como sua aplicação em informações divulgadas em notas explicativas das demonstrações financeiras;

- Do ponto de vista pragmático, são fornecidas ferramentas que possibilitem a executivos, órgãos reguladores, analistas de mercado, instituições educacionais, além de outros usuários da informação contábil, entender e melhorar os processos de divulgação e, consequentemente, de interpretação das informações contábilfinanceiras.

\section{REFERENCIAL TEÓRICO}

\subsection{Divulgação}

Divulgação é um conceito genérico da Contabilidade sobre a informação contábilfinanceira diferenciada transmitida pela entidade para os vários tipos de usuários (Iudícibus, 2010).

O foco central da divulgação está associado à representação fidedigna, ou seja, esse propósito é obtido através da conformidade das divulgações com os Pronunciamentos Técnicos, Interpretações e Orientações do CPC aplicáveis a fim de não tornar as demonstrações contábeis enganosas.

Uma divulgação em conformidade com tais requerimentos significa uma informação contábil-financeira com o objetivo de apresentar a substância econômica da transação ou evento que se pretende representar ("essência sobre a forma"). Assim, a divulgação não estaria evidenciando informações contábil-financeiras enganosas aos seus usuários.

As demonstrações contábeis, pelo meio das quais se dá à veiculação de informação contábil-financeira, é um conjunto de demonstrativos que inclui: balanço patrimonial; demonstração do resultado e do resultado abrangente; demonstração das mutações do patrimônio líquido; demonstração do fluxo de caixa; demonstração do valor adicionado (no ambiente Brasileiro); e notas explicativas.

Para Hendriksen e Michael F. (1999), as notas explicativas fornecem informações que não podem ser apresentadas adequadamente no corpo de uma demonstração sem reduzir a sua clareza e não devem ser usadas como substituto de classificação, avaliação e descrição apropriadas às demonstrações, tampouco devem contradizer ou repetir informações já contidas nas mesmas. 
A abordagem de Hendriksen e Michael F. (1999) pertence a um cenário histórico em que as divulgações em notas explicativas eram explicações diretas sobre os principais itens das demonstrações primárias. Isso incluía a exposição das políticas contábeis aplicadas à preparação das demonstrações contábeis pela entidade que reporta e a desagregação dos itens das demonstrações primárias em componentes menores para permitir ao usuário compreender as movimentações do balanço patrimonial ("quadros suplementares"). As notas explicativas eram vistas como notas de rodapé dos elementos das demonstrações primárias.

Contudo, nos últimos anos, houve um aumento das informações divulgadas em notas explicativas, decorrente, principalmente, dos desafios surgidos com a complexidade dos modelos de negócios, fontes de riscos e incertezas e de como a administração gerencia tais riscos e incertezas. Esse acréscimo consiste em uma resposta para satisfazer o desejo dos usuários de obter informações relevantes em um momento em que os negócios e o mercado de capitais tornam-se cada vez mais sofisticados, mesmo sendo essas informações mais subjetivas e menos confiáveis, ainda de acordo com o IAASB (2011).

A normatização e a prática da divulgação em notas explicativas acompanharam essas mudanças e passaram de simples quadros suplementares e informações sobre políticas contábeis para uma divulgação muito mais detalhada, incluindo a apresentação de estimativas sobre incertezas, modelos, bases de mensurações alternativas.

Atualmente, as divulgações em notas explicativas contêm uma quantidade ampla de informações não mais obtidas diretamente do sistema contábil da entidade que reporta, mas preditivas e com modelos e estimativas de incerteza.

\subsection{Razões para o excesso de divulgação em notas explicativas}

Parte do aumento das informações divulgadas em notas explicativas refere-se a informações não materiais, cuja apresentação seria dispensável.

Most (1977) já havia alertado que, mesmo em países onde a divulgação era regulamentada, existia o problema de muitas Companhias apresentarem no seu relatório anual mais informações do que realmente era necessário.

O IASB (2013) também está conduzindo uma iniciativa para encontrar um meio de aperfeiçoar as divulgações requeridas pelo IFRS e a anunciou, ao público geral, em janeiro de 2013, através de um fórum de discussão sobre as divulgações nas demonstrações financeiras, o projeto conhecido como "Disclosure Initiative", que se divide em diversos projetos de pesquisa como: materiality, principles of disclosure, standard level review disclosures, projeto de implementação: proposed Amendments to IAS 7, e projetos complementares: amendments to IAS 1.

Segundo o Disclosure Initiative, a causa para tal excesso de divulgação de informações não materiais nas demonstrações financeiras ainda não é certa, mas existem indicadores que apontam para as seguintes razões:

- Materialidade: o conceito de materialidade é bem compreendido por todos, contudo foram identificados problemas sobre a aplicação da materialidade no contexto das demonstrações financeiras;

- Abordagem do disclosure checklist com objetivo de identificar omissões de divulgações;

Revista ENIAC Pesquisa, Guarulhos (SP), V.6, n.2, jun.- dez. 2017 
- Falta de clareza de determinados pronunciamentos quanto a divulgações de informações contábil-financeiras;

- Percepção de que alguns pronunciamentos exigem divulgações ao invés de estimular o julgamento dos preparadores e auditores;

- Barreiras legais e institucionais;

- Falta de tempo e recurso para preparar e divulgar as demonstrações financeiras; e

- Falta de comunicação entre preparadores e usuários (IASB - AP8, 2013, traduzido pelo autor).

O Disclosure Initiative ainda é um projeto em fase de desenvolvimento que, consequentemente, não chegou a uma conclusão geral a respeito desse problema.

O FRC (2009) - Financial Reporting Council - realizou entrevistas que possibilitaram um entendimento sobre os seguintes fatores coadjuvantes para o aumento das divulgações não materiais em notas explicativas:

- Devido à pressão do tempo para a emissão das demonstrações financeiras, os preparadores apenas repetem as informações divulgadas em anos anteriores ao invés de avaliarem se elas ainda são materiais;

- Falta de confiança ao se fazerem julgamentos a respeito de divulgações que são ou não materiais;

- É exigido muito trabalho do preparador para se concluir o que é ou não uma divulgação material a ser inclusa nas demonstrações financeiras;

- Desejo de se evitar longas discussões com os auditores;

- Seguindo o líder: se uma Companhia divulga determinada informação, ela influencia as demais a divulgar também; e

- Os preparadores e auditores temem o questionamento dos órgãos reguladores sobre informações não divulgadas (FRC, 2009, p. 42, traduzido pelo autor).

De maneira geral, conforme o FRC (2009), se um pronunciamento requer determinada divulgação, o preparador incluirá tal exigência nas demonstrações financeiras, independente de suas considerações a respeito da materialidade.

Pode-se notar a semelhança entre o FRC (2009) e o Disclosure Initiative (IASB, 2013) quanto às possíveis causas para o aumento de informações não materiais nas demonstrações financeiras.

O EFRAG (2012) também destacou os seguintes motivos que deterioram as divulgações em notas explicativas:

a) Tentativa de aprimorar o nível de transparência das divulgações por meio da emissão de novos pronunciamentos. Dessa maneira, as notas explicativas passaram a ser vistas como um depósito de informações em que quanto mais dados forem divulgados, menor é a chance de acontecer um desastre financeiro. As notas explicativas tornaram-se um caminho para se compensarem as deficiências de reconhecimento e mensuração, deixando de ser notas suplementares das informações divulgadas nas demonstrações primárias;

b) As transações e exigências de divulgação das demonstrações contábeis aumentaram em nível de complexidade; 
c) Existe uma dificuldade em aplicar o conceito de materialidade para as divulgações em notas explicativas;

d) Os preparadores, auditores e órgãos reguladores aplicam o checklist de divulgações como medida de segurança para apresentação das demonstrações financeiras; e

e) Pressões de tempo para emissão das demonstrações financeiras dão origem a formas alternativas para comunicação de informações contábil-financeiras ao mercado financeiro (exemplo: press releases) (EFRAG, 2012, p. 6, traduzido pelo autor).

Assim, uma das principais causas da divulgação de informações não materiais nas notas explicativas é a falta de um guia para aplicação da materialidade sobre as exigências de divulgação requeridas pelos pronunciamentos técnicos, decorrentes do aumento da complexidade dos eventos econômicos, exigindo modelos de reconhecimento, mensuração e divulgações cada vez mais sofisticados.

Dessa forma, torna-se necessário reavaliar como as informações são divulgadas em notas explicativas com o intuito de permitir ao preparador identificar quais realmente são as informações materiais e proporcionar ao usuário a oportunidade de confiar nestas, para formar os seus próprios julgamentos sobre a entidade analisada.

\subsection{Materialidade}

Para Riahi-Belkaoui (2004), a materialidade refere-se a transações e eventos que possuem um efeito econômico insignificante e, consequentemente, podem ser tratados da forma menos custosa possível independentemente se estão ou não de acordo com os princípios de contabilidade geralmente aceitos. Ela serve como um guia implícito para o contador determinar o conteúdo a ser divulgado nas demonstrações financeiras, permitindo a ele decidir o que não é importante ou não é interessante em termos de registro, acurácia e relevância.

Em consonância com essa definição, Iudícibus (2010) comenta que a materialidade tem relação com a noção de custo versus benefício da informação contábil gerada. A contabilidade pode ser feita com requintes de detalhes visando à sua perfeição e estes, na verdade, revelamse imateriais, pois o benefício adicional ocasionado pela informação é superado pelo custo (mensurado também em tempo) para gerá-la.

Partindo-se do ponto de vista do usuário, de acordo com Iudícibus (2010), qualquer informação contábil é material, uma vez que a sua omissão nos demonstrativos publicados ou nas notas de evidenciação pode propiciar um julgamento equivocado sobre a situação da entidade, principalmente quanto ao estabelecimento de tendências.

Assim, itens materiais representam, normalmente, números significativos para o porte da entidade devido à sua potencial influência nas decisões dos usuários.

A materialidade é um conceito pervasivo e relaciona-se com a determinação da forma de registro e divulgação do item seja agregado ou individualizado de acordo com a sua natureza, valor e divulgação, como também com a respectiva divulgação qualitativa, principalmente, 
quando o item tem a capacidade de influenciar na decisão do usuário. Portanto, é fundamental designar um parâmetro sobre o que é ou não material a fim de orientar o próprio julgamento do preparador das demonstrações contábeis. Sem esse determinado parâmetro, toda a discussão sobre a materialidade torna-se vaga, pois não há como inferir se o julgamento é ou não adequado como forma de representação de uma realidade econômica em cifras contábeis.

Most (1977) sugere um meio para a determinação da materialidade ao constatar que não existe algo como a materialidade, pois ela é simplesmente um aspecto da relevância, havendo apenas itens materiais. Portanto, a materialidade não é simplesmente algo abstrato, ao possuir um vínculo com o espaço físico: os itens registrados.

Ao se interpretar o que é material para a preparação das demonstrações contábeis, a materialidade passa a depender tanto de fatores quantitativos como qualitativos, ou seja, um item ou uma informação pode ser material por conta do seu montante e/ou pela sua natureza, pois as divulgações em notas explicativas incluem descrições quantitativas ou apenas qualitativas. Contudo, esses dois elementos sempre estão relacionados. Por exemplo, não se requer explicar qualitativamente uma operação rotineira como uma transação sobre vendas, mesmo que seja relevante, se ela obedece aos critérios de reconhecimento já divulgados na nota de política contábil, ou explicar uma variação do ano anterior para o atual em relação a outras obrigações quando o valor e a variação do saldo são imateriais para ambos os exercícios.

Carmichael, Willingham, \& Schaller (1996) explicam que, para estimar e aplicar o percentual para a materialidade, é fundamental selecionar uma base (ou como citado nas NBC TA 320: "referencial"). Segundo os autores, a medida do percentual aplicável é uma decisão baseada no julgamento muitas vezes estabelecido por critérios diferentes entre as firmas de auditorias, as quais utilizam a "rule-of-thumb" para estimar a materialidade, conforme se verifica na tabela a seguir:

Tabela 1: Benchmark para cálculo da materialidade

\begin{tabular}{|l|l|l|}
\hline Base & Intervalo & Vantagens \\
\hline Lucro das atividades continuadas antes dos impostos & $5-10 \%$ & Relevância \\
\hline Total da receita & $0,5-2 \%$ & Estabilidade \\
\hline Total dos ativos & $0,5-2 \%$ & Previsibilidade e estabilidade \\
\hline
\end{tabular}

Fonte: Carmichael, Willingham, \& Schaller, 1996, p. 140

O cálculo da materialidade pode ser resumido através dos seguintes passos:

1. Determinação de um referencial adequado;

2. Estabelecimento do valor apropriado do referencial, selecionando-o a partir das demonstrações contábeis da entidade e ajustando-o para transações ou quaisquer outros eventos não usuais, quando aplicáveis; e

3. Uso do julgamento profissional para definir o percentual aplicado sobre o referencial para o cálculo da materialidade considerando as demonstrações contábeis em sua integralidade.

Para Carmichael, Willingham, \& Schaller (1996), a escolha de um entre os três referenciais depende do julgamento profissional sobre relevância, estabilidade e 
previsibilidade. Nesse contexto, as receitas operacionais ou o lucro antes de impostos de operações continuadas são frequentemente usados para Companhias de Capital Aberto por serem informações importantes para o investidor, pois esses acionistas possuem como meta o fluxo regular de dividendos, lucro por ação. Contudo, o lucro antes dos impostos de operações continuadas pode estar sujeito a variações significativas e, assim, esse referencial pode não ser o mais recomendado para o cálculo da materialidade para uma entidade sem fins lucrativos.

\section{METODOLOGIA}

\subsection{Equação adotada para o teste empírico}

Conforme Tsalavoutas, Evans \& Smith (2010), há alguns estudos que desenvolveram técnicas para mensurar se as companhias estão ou não preparando suas demonstrações contábeis de acordo com as divulgações requeridas pelos Pronunciamentos Técnicos.

A maior parte dessas pesquisas emprega o índice dicotômico, desenvolvido por Cooke (1992), Cooke's dichotomous approach, para mensurar o quanto as demonstrações contábeis aderem aos requerimentos de divulgação.

Este método atribui 1 ponto quando a Companhia adere ao requerimento de divulgação e, quando não, é computado o valor 0 .

O índice dicotômico é calculado, para cada demonstração contábil, como uma razão entre o total de itens divulgados e a nota máxima a ser atribuída para essa demonstração financeira, conforme fórmula apresentada por Tsalavoutas, Evans \& Smith (2010):

$$
C_{j}=\frac{T=\sum_{i=1}^{n} d_{i}}{M=\sum_{i=1}^{m} d_{i}}
$$

Onde:

$C_{j}$ : $\quad$ Total computado sobre o quanto a demonstração contábil $(j)$ foi apresentada de acordo com os requerimentos técnicos. O índice varia no intervalo de $0 \leq C_{j} \leq 1$

T: $\quad$ Número total de itens divulgados $\left(d_{i}\right)$ na demonstração contábil $(j)$ 
M: $\quad$ Número máximo de divulgações passíveis de evidenciação na demonstração contábil $(j)$.

$\mathrm{O}$ índice é composto por 17 perguntas as quais tiveram como base o Towards a Disclosure Framework for the Notes (EFRAG, 2012), estudo em que foram apresentados os indicadores sobre a necessidade de divulgações de informações materiais e de informações adicionais. As perguntas estão detalhadas no Apêndice I e para cada resposta:

- A nota 0 é atribuída para divulgação de informações não materiais, ou seja, aquelas que não deveriam ser evidenciadas; e

- A nota 1 é atribuída para divulgações que atendam ao critério de divulgação de acordo com a materialidade calculada e os indicadores de divulgação das 17 perguntas.

\subsection{Descrição do índice dicotômico}

O índice dicotômico usado nesse estudo engloba quatro dimensões de informações descritas a seguir:

- Sobre as principais políticas contábeis (três perguntas): essa dimensão relaciona os elementos materiais divulgados no balanço patrimonial, a demonstração do resultado, a demonstração do resultado abrangente com suas respectivas políticas contábeis.

- A respeito dos dados financeiros das notas explicativas (seis perguntas): nesse âmbito, relacionam-se os elementos materiais do balanço patrimonial, demonstração do resultado, demonstração do resultado abrangente com as evidenciações quantitativas e qualitativas contidas nos quadros das notas explicativas.

- Outros dados contratuais (três perguntas): essa dimensão trata da apresentação de informações materiais relacionadas a: (i) restrição de uso de ativos; (ii) condições contratuais específicas; e (iii) incertezas originadas de obrigações, direitos e arranjos contratuais.

- Acerca dos riscos aos quais a entidade está sujeita (cinco perguntas): esse âmbito trata da exposição de dados sobre o risco de crédito, liquidez e de mercado quando estão relacionados a elementos materiais das demonstrações contábeis. 


\subsection{Descrição da amostra}

O processo de amostragem é não probabilístico e a técnica utilizada é intencional. Dessa forma, os índices foram apurados para as duas únicas Companhias de Capital Aberto do Setor de Construção e Transporte, pertencentes ao Subsetor de Transporte e do Segmento Rodoviário, sendo elas: JSL e Tegma. O segmento rodoviário foi escolhido devido à importância desse setor na economia brasileira por ter a maior representatividade entre os modais de transportes existentes, de acordo com o Relatório Anual da Agência Nacional de Transportes Terrestres 2012 (ANTT, 2012).

Os questionários para apuração do índice dicotômico foram preenchidos a partir das demonstrações contábeis relativas aos exercícios findos em 31 de dezembro de 2014 e 2013, acessíveis no endereço eletrônico de cada empresa ou das Demonstrações Financeiras Padronizadas disponíveis na CVM.

\subsection{Cálculo da materialidade para a amostra selecionada}

Os dois quadros a seguir evidenciam o cálculo da materialidade para a JSL e Tegma considerando as seguintes premissas:

1. Determinação de um referencial adequado: Como a JSL e a Tegma são duas Companhias Abertas com ações negociadas na BM\&FBOVESPA e com fins lucrativos, é empregada a receita líquida consolidada como referencial satisfatório.

2. Valor apropriado do referencial: a receita líquida consolidada é obtida, tanto para a JSL quanto para a Tegma, das demonstrações contábeis de 31 de dezembro de 2014, de acordo com a sua divulgação no endereço eletrônico das empresas, na seção "relação com investidores" da JSL e Tegma.

3. Percentual aplicado sobre o referencial: como ambas Companhias não apresentam ressalvas no relatório do auditor independente, julga-se que as demonstrações financeiras estão apresentadas de acordo com as práticas contábeis adotadas no Brasil e as normas internacionais de relatório financeiro (IFRS) emitidas pelo International Accounting Standards Board (IASB). A partir da opinião sem ressalva do auditor independente, justifica-se a utilização do percentual máximo de $2 \%$ aplicado sobre a receita para estimar a materialidade porque o risco das informações divulgadas apresentar um erro material é baixo. O percentual é arbitrário ("rule-of-thumb"), recolhido da Tabela 1: benchmark para o cálculo da materialidade, elaborado por Carmichael, Willingham \& Schaller (1996, p. 140) e presente na seção 2.3 Materialidade.

Sendo assim, nas tabelas a seguir, verifica-se a materialidade calculada para as Companhias: 
a) JSL

Tabela 2: Cálculo da materialidade para 2014 - JSL

\begin{tabular}{|l|l|c|}
\hline & & Em milhares de reais \\
\hline & Receita líquida & 5.539 .194 \\
\hline$(\mathrm{x})$ & Percentual aplicado sobre o referencial & $2 \%$ \\
\hline$(=)$ & Materialidade & 110.784 \\
\hline
\end{tabular}

Fonte: Elaborado pelo autor, 2017.

b) Tegma

Tabela 3: Cálculo da materialidade para 2014 - Tegma

\begin{tabular}{|l|l|c|}
\hline & & Em milhares de reais \\
\hline & Receita líquida & 1.439 .553 \\
\hline$(\mathrm{x})$ & Percentual aplicado sobre o referencial & $2 \%$ \\
\hline$(=)$ & Materialidade & 28.791 \\
\hline
\end{tabular}

Fonte: Elaborado pelo autor,2017.

\subsection{Limitação da pesquisa}

A pesquisa possui as limitações descritas a seguir:

- O pesquisador deve exercer julgamento para decidir se a Companhia atende ou não ao critério de divulgação da informação de acordo com a materialidade calculada. Houve a tentativa de evitar que a Companhia analisada fosse penalizada devido a uma resposta não aplicável ou negativa em relação a um determinado critério de divulgação por meio da leitura completa das Demonstrações Contábeis antes da aplicação do método, segundo orientação de Cooke (1992).

- Conforme as NBC TA 320 (2009), a determinação da porcentagem a ser aplicada ao referencial selecionado envolve o exercício de julgamento profissional. O percentual utilizado de $2 \%$ é arbitrário e tem como base a tabela 1 desenvolvida por Carmichael, Willingham \& Schaller (1996). A escolha do referencial também foi arbitrária, de modo que o uso de um outro referencial implicaria em resultados diferentes do alcançados.

- Não houve acesso à informação interna das Companhias selecionadas (JSL e Tegma). Sendo assim, podem existir motivos para divulgação de informações não materiais considerados relevantes pela administração dentro do contexto em que a entidade opera. Da mesma forma, não se obteve acesso a informações internas para concluir se há informações materiais que deveriam ser apresentadas e não foram. Porém, essa última questão é mitigada pelo relatório dos auditores independentes de ambas Companhias sem ressalva, pois se há omissão de divulgações materiais, é preciso incluir-se uma ressalva no relatório dos auditores independentes.

- É um exercício de simulação e não significa que ela deva ser usada como regra.

- Como a amostra é composta por duas companhias, os resultados obtidos não se dirigem aos elementos representativos da população em geral (Companhias listadas na BM\&FBOVESPA). Assim, aceitas as limitações técnicas, é impraticável 
generalizar os resultados da pesquisa à população das Companhias Abertas. Esse estudo é válido para as duas Companhias estudadas.

\section{RESULTADOS}

\subsection{Resultado geral da pesquisa}

A Tabela 4 a seguir expõe o resultado do índice dicotômico modificado para cada uma de suas quatro dimensões.

Tabela 4: Índice Dicotômico Geral

\begin{tabular}{|l|c|c|}
\hline & JSL & Tegma \\
\hline Informações sobre as principais políticas contábeis & 0,71 & 0,66 \\
\hline Informações sobre os dados financeiros das notas explicativas & 0,56 & 0,73 \\
\hline Outras informações contratuais & 0,75 & 0,80 \\
\hline Informações sobre os riscos a que a entidade está sujeita & 0,88 & 1,00 \\
\hline
\end{tabular}

Fonte: Elaborada pelo autor, 2017.

A dimensão de informações sobre os dados financeiros é o grupo em que foi computado o menor percentual do índice dicotômico modificado para JSL e a dimensão a respeito das políticas contábeis é a categoria em que se apurou o menor percentual do índice dicotômico modificado para a Tegma. Em compensação, ambas Companhias obtiveram o maior resultado para a dimensão de informações sobre os riscos a que a entidade está sujeita. As condições gerais sobre o resultado da análise encontram-se descritas a seguir.

\subsubsection{Considerações gerais sobre o resultado das principais politicas contábeis}

A dimensão que apresentou o maior número de questões foi a de informações sobre as principais políticas contábeis. Essa dimensão representou o menor resultado obtido para a Tegma.

A JSL apresentou 18 informações imateriais para 63 respostas possíveis e a Tegma, 20 informações imateriais para 59 respostas possíveis.

As duas primeiras questões dessa dimensão estão intrinsicamente relacionadas porque quando a Companhia divulga uma política contábil, geralmente ela apresenta na mesma Nota Explicativa a forma de reconhecimento e mensuração do respectivo elemento. As similaridades de divulgações sobre informações não materiais para as duas Companhias, nessa dimensão, ocorreram, principalmente, em relação às seguintes transações: combinação de negócio, investimento, instrumentos financeiros e pagamentos baseados em ações. Desse modo, as mesmas conclusões são aplicáveis para esse caso.

Uma possível explicação para a divulgação, pela JSL e Tegma, dos elementos não materiais identificados é a complexidade na forma de identificação, mensuração e reconhecimento relacionadas a essas transações. Segundo o FRC (2009), essa complexidade está associada à falta de confiança pelos preparadores e auditores ao julgar entre o que é ou não 
material para ser divulgado e receio de que, caso as informações não sejam divulgadas para essas transações, a Companhia possa vir a ser questionada pelos órgãos reguladores sobre a ausência de evidenciação.

Quanto à divulgação relativa aos investimentos, a pesquisa apenas considera como informação não material aquela relacionada às demonstrações financeiras consolidadas de ambas Companhias, pois a análise está fundamentada no Grupo Econômico e não nas demonstrações contábeis da controladora.

Também se verificou para a terceira questão dessa dimensão a divulgação de informações sobre a revogação da RTT e aplicação de novas normas, alterações e interpretações de normas que ainda não estão em vigor. A administração analisou o primeiro caso e concluiu que não há efeitos significativos e, para o segundo, não são esperados efeitos relevantes, ou seja, sem impacto material nas demonstrações contábeis. Assim, essas divulgações poderiam ser dispensadas, com base nos critérios adotados nessa pesquisa. Todavia, acredita-se em que as Companhias tenham divulgado essa informação em conformidade com a exigência do CPC 23 que não abre considerações sobre a aplicação de uma materialidade no seu texto, por empregar o imperativo "deve":

Quando a entidade não adotar antecipadamente novo Pronunciamento, Interpretação ou Orientação já emitidos, mas ainda não com aplicação obrigatória, a entidade deve divulgar: (a) tal fato; e (b) informação disponível ou razoavelmente estimável que seja relevante para avaliar o possível impacto da aplicação do novo Pronunciamento, Interpretação ou Orientação nas demonstrações contábeis da entidade no período da aplicação inicial (CPC 23, 2009, item 30).

\subsubsection{Considerações gerais sobre os dados financeiros das notas explicativas}

A segunda dimensão representou o menor resultado obtido para a JSL devido às divulgações de composições e informações qualitativas sobre elementos imateriais do balanço patrimonial e da demonstração de resultado.

A JSL apresentou 24 informações imateriais para 54 respostas possíveis e a Tegma, 13 informações imateriais para 49 respostas possíveis.

Ambas Companhias mostraram similaridades sobre as principais divulgações de informações não materiais para as seguintes transações ou eventos: ações em tesouraria, partes relacionadas, combinação de negócio, instrumentos financeiros, pagamento baseado em ações e investimento.

Em relação ao caso das ações em tesouraria, nota-se que a divulgação foi feita, provavelmente, em cumprimento à instrução CVM 010/80.

As divulgações sobre partes relacionadas constituem-se em uma questão de difícil interpretação devido ao texto do pronunciamento técnico CPC 05, o qual define como relevantes essas transações, sem consideração de uma materialidade. Por exemplo, o texto retirado deste pronunciamento exige a divulgação das relações entre partes relacionadas, mesmo que não existam transações entre elas:

Revista ENIAC Pesquisa, Guarulhos (SP), V.6, n.2, jun.- dez. 2017 
...a demonstração do resultado e o balanço patrimonial da entidade podem ser afetados por um relacionamento com partes relacionadas mesmo que não ocorram transac̃̃es com essas partes relacionadas (CPC 05, 2010, item 7).

Em consonância com as interpretações obtidas com os estudos discutidos no capítulo 2, as informações sobre combinações de negócios, instrumentos financeiros e pagamento baseado em ações foram divulgadas devido à complexidade da forma de mensuração e reconhecimento dessas transações. Tais aspectos suscitaram a falta de confiança do preparador e auditor ao se fazerem julgamentos a respeito da materialidade e o receio da Companhia de ser questionada pelo órgão regulador caso não divulgasse a respectiva informação.

\subsubsection{Considerações gerais sobre outras informações contratuais}

Destaca-se, para a dimensão sobre outras informações contratuais, a divulgação por ambas Companhias de processos jurídicos com impactos inferiores à materialidade. As divulgações de informações não materiais para as três questões dessa dimensão estão relacionadas com requerimentos de divulgações contidos em normas cuja referência para a aplicação da materialidade é obscura. Por exemplo, o texto do CPC 25 (2009) requer que seja divulgada uma breve explicação da natureza da obrigação mencionando a palavra deve (imperativo) e sem fazer referência ao uso da materialidade.

\subsubsection{Considerações gerais sobre os riscos que a entidade está sujeita}

Já a dimensão que apresentou o maior resultado para as duas Companhias foi a dos riscos a que a entidade está sujeita. Somente a JSL divulgou a análise de sensibilidade para a variação do dólar em relação ao real e do IPCA, contudo, o impacto no patrimônio líquido e no resultado é inferior à materialidade. Justifica-se a divulgação dessa informação não material em decorrência do texto da Instrução CVM 475 - Instrumentos Financeiros o qual obriga a divulgação da análise de sensibilidade quando o risco de mercado é considerado relevante sem a consideração sobre a materialidade. Dessa forma, o texto requer a utilização do julgamento da administração para decidir o que é ou não relevante e, dessa forma, opta-se pela divulgação da informação a fim de se evitar um possível questionamento do órgão regulador devido à ausência da divulgação.

Outra razão discutida no referencial teórico e ligada a informações não materiais divulgadas pela JSL e Tegma é a falta de tempo para preparar e divulgar as demonstrações financeiras, considerando que ambas são Companhias Abertas e devem atender ao tempo limite de divulgação imposto pela CVM de três meses, conforme a própria CVM 480 (2009).

\section{CONCLUSÃO}

O objetivo dessa pesquisa consistiu na busca pela resposta à questão principal sobre como o conceito de materialidade pode ser aplicado para as informações divulgadas em notas explicativas.

Por meio do estudo efetuado, verificou-se que a materialidade pode ser considerada como o resultado de um cálculo derivado das seguintes premissas: (i) determinação de um 
referencial; (ii) valor apropriado para o referencial ajustado para qualquer transação não usual; e (iii) definição de um percentual para ser aplicado sobre o referencial selecionado.

O resultado do cálculo, ou seja, a materialidade, é o parâmetro para identificar quais são as informações quantitativas e qualitativas que podem influenciar as decisões dos usuários das demonstrações contábeis e, dessa maneira, devem ser divulgadas.

O pressuposto básico dessa pesquisa para aplicar o conceito de materialidade sobre as divulgações em notas explicativas foi analisar se as informações quantitativas e qualitativas das notas explicativas correspondem a dados quantitativos materiais das demonstrações primárias.

Dessa forma, o presente estudo entende que as informações quantitativas e qualitativas estão intrinsicamente relacionadas, pois não se requer explicar qualitativamente um evento ou transação quando o seu impacto quantitativo no relatório contábil é inferior à materialidade.

Observa-se que uma das razões para considerar a materialidade um conceito complexo e sujeito a diversas interpretações é a falta de uma definição operacional para o seu cálculo, sendo que os Pronunciamentos, Interpretações e Orientações Técnicas corroboram mais o julgamento do contador para determinar o que é ou não material, ao invés de estabelecerem guias práticos para a sua aplicação.

Portanto, aceita-se a hipótese da existência de um índice de materialidade que permite ao preparador identificar quais são as informações úteis para divulgação em notas explicativas.

O estudo também investigou se as demonstrações financeiras da J.S.L e Tegma, de 31 de dezembro de 2014, apresentaram informações não materiais por meio de critérios estabelecidos nessa pesquisa e da aplicação do índice dicotômico modificado sobre as divulgações em notas explicativas relacionadas ao balanço patrimonial e demonstração do resultado.

O índice dicotômico modificado foi utilizado para analisar 141 questões para JSL, das quais 47 obtiveram nota 0 ; e na análise de 93 questões para Tegma, 36 obtiveram nota 0 . Por conseguinte, quanto às informações divulgadas nas Demonstrações Financeiras, 33\% da JSL e $28 \%$ da Tegma poderiam não ter sido divulgadas com base na materialidade estabelecida com base nos critérios definidos nessa pesquisa para as respectivas Companhias.

As informações não materiais divulgadas nas notas explicativas de ambas Companhias sugerem que: (i) eventos e transações com formas de mensuração e reconhecimento complexas implicam a falta de confiança dos preparadores e auditores para se fazerem julgamentos a respeito da materialidade; (ii) há uma preocupação por parte da Companhia de ser questionada pelo órgão regulador caso alguma informação relacionada a um evento ou transação complexa não seja divulgada; (iii) exigências de divulgações requeridas por Pronunciamentos, Interpretações, Orientações Técnicas e normas legais não consideram a materialidade de uma entidade específica; e (iv) há limitações de tempo para preparar e divulgar as demonstrações financeiras.

Essas sugestões sobre as causas das divulgações de informações não materiais em notas explicativas corroboram as conclusões alcançadas pelos estudos do FRC, IASB, IAASB e EFRAG e foram utilizadas nessa pesquisa como explicação para o fenômeno observado devido a semelhanças identificadas.

Revista ENIAC Pesquisa, Guarulhos (SP), V.6, n.2, jun.- dez. 2017 
Dessa forma, a segunda hipótese, de que as companhias abertas do segmento de transporte rodoviário do Bovespa divulgam apenas informações materiais nas notas explicativas, é rejeitada.

Como considerações gerais alcançadas, destaca-se que, para atender os objetivos de limitar as discussões e eliminar a informação não material das notas explicativas, é necessário estabelecer um guia prático para aplicação da materialidade sobre estas, considerando a possibilidade de se constituírem critérios para o seu cálculo, servindo de parâmetro para determinar a relevância da informação a ser divulgada.

Como sugestão para futuras pesquisas, propõe-se:

- Investigar o motivo que induz os preparadores a divulgarem informações imateriais e se esta atitude está relacionada com a revisão dos órgãos reguladores e solicitações de reapresentação das demonstrações financeiras para a inclusão de informações imateriais no relatório contábil-financeiro.

- Um estudo estático e crítico sobre a forma de calcular a materialidade para preparação das demonstrações financeiras. Como essa pesquisa demonstrou, existe a necessidade de se determinarem parâmetros quantitativos para estabelecer a materialidade, a fim de tornar esse conceito "operacional", a partir da redução dos julgamentos dos preparadores sobre o que é ou não material. Entende-se que simplesmente determinar a materialidade com base em um percentual e referencial qualquer não é o mais adequado, contudo, acredita-se na possibilidade da utilização de modelos estatísticos para definir parâmetros quantitativos resultantes em um alto grau de confiabilidade sobre quais informações quantitativas e qualitativas influenciam de fato a tomada de decisão do investidor.

\section{REFERÊNCIAS}

AGÊNCIA NACIONAL DE TRANSPORTES TERRESTRES (ANTT). Relatório Anual da ANTT 2012. Disponível em: http://www.transportes.gov.br/conteudo/53887.

BRASIL. Instrução CVM No 475, de 17 de dezembro de 2008. Disponível em: http://www.cvm.gov.br/legislacao/inst/inst475.html.

. Instrução CVM N 480 , de 7 dezembro de 2009 com as alterações introduzidas pelas Instruções CVM No 488/10, 509/11, 511/11, 520/12, 525/12, 547/14 e 552/14.

- Ministério dos Transportes. Transporte Rodoviário do Brasil. Disponível em: http://www2.transportes.gov.br/bit/02-rodo/rodo.html.

CARMiCHAEL, D. R.; WILlingHAM, J. J.; SCHALLER, C. A. Auditing concepts and methods: a guide to current theory and practice. New York: McGraw-Hill, 1996.

COMITÊ DE PRONUNCIAMENTOS CONTÁBEIS - CPC. CPC - Estrutura Conceitual para Elaboração e Divulgação de Relatório Contábil-Financeiro (R1). Brasília, 2011.

. CPC 05 - Divulgação sobre partes relacionadas. Brasília, 2010.

Revista ENIAC Pesquisa, Guarulhos (SP), V.6, n.2, jun.- dez. 2017 
. CPC 23 - Políticas Contábeis, Mudança de Estimativas e Retificação de Erros. Brasília, 2009.

. CPC 25 - Provisões, Passivos Contingentes e Ativos Contingentes. Brasília, 2009.

COMITÊ DE PRONUNCIAMENTOS CONTÁBEIS, ORIENTAÇÃO TÉCNICA. OCPC 07

- Evidenciação na Divulgação dos Relatórios Contábil-Financeiros de Propósito Geral. Brasília, 2014.

COOKE, T. The impact of size, stock market listing and industry type on disclosure in the annual reports of Japanese listed corporations. Accounting and Business Research 22, pp. 229 237. 1992.

EFRAG - European Financial Reporting Advisory Group. Towards a Disclosure Framework for the Notes. Julho, 2012. Disponível em: http://www.efrag.org/Front/n2-972/DiscussionPaper---Towards-a-Disclosure-Framework-for-the-Notes.aspx.

FRC - Financial Reporting Council. Louder than Words. London: FRC, June 2009.

HENDRIKSEN, E. S. V. B.; Michael, F. Teoria da contabilidade. São Paulo: Atlas. 1999.

IASB - International Accouting Standard Board. The conceptual Framework for Financial Reporting London. IASB - BV, 2011 Blue Book.

International Accounting Standard Board. 2013. AP8A - September 2013 IASB

Meeting: Disclosure initiative, an overview. Setembro, 2013. Disponível em:

http://www.ifrs.org/Current-Projects/IASB-Projects/Disclosure-Initiative/Pages/DisclosureInitiative.aspx.

International Accounting Standard Board. 2013. Staff papper: Materiality. Novembro, 2014. Disponível em:

http://www.ifrs.org/Meetings/MeetingDocs/IASB/2014/November/AP11C-

Disclosure\%20Initiative.pdf.

IAASB - International Auditing and Assurance Standard Board. Discussion Paper, The Evolving Nature of Financial Reporting: Disclosure and Its Audit Implications. Janeiro, 2011. Disponível em: http://www.ifac.org/sites/default/files/publications/exposure-drafts/IAASBDisclosures_Discussion_Paper.pdf.

IBRACON - Instituto dos Auditores Independentes do Brasil. Estrutura Conceitual Básica da Contabilidade. São Paulo, 1987.

IUDÍCIBUS, S. Teoria da Contabilidade. 10 ed. São Paulo: Atlas. 2010.

JSL S.A. Demonstrativos Financeiros - DFP 2013. Disponível em: $\mathrm{http}: / /$ ri.jsl.com.br/conteudo_pt.asp?idioma $=0 \& \operatorname{conta}=28 \&$ tipo $=30649 \& \mathrm{id}=0 \&$ submenu $=0 \& \mathrm{i}$ $\mathrm{mg}=0 \& \mathrm{ano}=2014$. 
JSL S.A. Demonstrativos Financeiros - DFP 2014. Disponível em: http://ri.jsl.com.br/conteudo_pt.asp?idioma $=0 \& \operatorname{conta}=28 \&$ tipo $=30649 \& \mathrm{id}=0 \&$ submenu $=0 \& \mathrm{i}$ $\mathrm{mg}=0 \& \mathrm{ano}=2015$.

MOST, K. S. Accounting theory. Columbus, Ohio: Grid. 1977.

PINHEIRO, P. B. A materialidade aplicada para divulgação de informações em notas explicativas. Dissertação (Mestrado) - Pontifícia Universidade Católica de São Paulo, São Paulo, SP, Brasil. 2015.

NORMAS BRASILEIRAS DE CONTABILIDADE. NBC TA 320 - Materialidade no Planejamento e na execução da Auditoria. Novembro, 2009. Disponível em: http://www.cfc.org.br/sisweb/sre/detalhes_sre.aspx?Codigo=2009/001213.

RIAHI-BELKAOUI, A. Accounting theory. 5th ed. Hampshire: Cengage Learning. 2004.

SEC - Securities and Exchange Comission (2011). An analysis of IFRS in practice. SEC Staff Paper. Setembro, 2012. Disponível em: www.sec.gov

TEGMA Gestão Logística S.A. Demonstrativos Financeiros - DFP 2014. Disponível em: http://ri.tegma.com.br/ShowResultado.aspx?IdResultado=fq85awYOuyLdaAr4qbHMQg==.

TSALAVOUTAS, I. EVANS, L. \& SMITH M. Comparison of two methods for measuring compliance with IFRS mandatory disclosure requirements. Journal of Applied Accounting Research, 11(3), pp. $213-228.2010$. 


\section{APÊNDICE}

\section{ÍNDICE DICOTÔMICO Companhia:}

\begin{tabular}{|c|c|c|}
\hline \multirow{2}{*}{$\begin{array}{l}\text { 1. Foram divulgadas nas notas explicativas apenas as políticas contábeis relacionadas a elementos } \\
\text { materiais do balanço patrimonial e das demonstraços do resultado? }\end{array}$} & Sim & Não \\
\hline & & \\
\hline \multicolumn{3}{|l|}{$\begin{array}{l}\text { 2. A política contábil relacionada ao elemento das demonstrações contábeis descreve adequadamente a } \\
\text { forma de reconhecimento e mensuração do elemento? }\end{array}$} \\
\hline \multicolumn{3}{|l|}{$\begin{array}{l}\text { 3. Inclui-se a divulgação de formas alternativas de reconhecimento e mensuração quando permitida e } \\
\text { impacto de novos pronunciamentos? }\end{array}$} \\
\hline \multicolumn{3}{|l|}{$\begin{array}{l}\text { 4. Foi apresentada, em uma nota explicativa específica, a explicação de um elemento material do balanço } \\
\text { patrimonial ou da demonstração de resultado quando a sua nomenclatura não foi suficiente para } \\
\text { compreensão da sua natureza? }\end{array}$} \\
\hline \multicolumn{3}{|l|}{$\begin{array}{l}\text { 5. Itens individuais agregados de atividades de negócios diferentes, apresentados como único elemento } \\
\text { no balanço patrimonial ou na demonstração de resultado, foram divulgados separadamente nas notas } \\
\text { explicativas quando maiores que a materialidade calculada? }\end{array}$} \\
\hline \multicolumn{3}{|l|}{$\begin{array}{l}\text { 6. Itens agregados para apresentação como um único elemento material no balanço patrimonial ou na } \\
\text { demonstração de resultado, com diferentes: } \\
\text { - bases de mensuração; } \\
\text { - sensibilidades a variação; } \\
\text { - formas de realização ou recuperação; } \\
\text { - direitos e obrigações; } \\
\text { - vencimentos } \\
\text { foram divulgados separadamente nas notas explicativas? }\end{array}$} \\
\hline \multicolumn{3}{|l|}{$\begin{array}{l}\text { 7. Itens do ativo e passivo ou da receita e despesa compensados quando exigidos ou permitidos por um } \\
\text { Pronunciamento Técnico, Interpretação ou Orientação do CPC foram apresentados nas notas explicativas } \\
\text { brutos quando maiores que a materialidade? }\end{array}$} \\
\hline \multicolumn{3}{|l|}{$\begin{array}{l}\text { 8. Foi divulgado, em nota explicativa, o mapa de movimentação desagregada o qual apresentou variação } \\
\text { material ou não usual relevante para o elemento de investimento ou financiamento do balanço } \\
\text { patrimonial? }\end{array}$} \\
\hline \multicolumn{3}{|l|}{$\begin{array}{l}\text { 9. Explicações sobre transação material com efeito pervasivo no balanço patrimonial e na demonstração } \\
\text { do resultado foram divulgadas em notas explicativas? }\end{array}$} \\
\hline \multicolumn{3}{|l|}{ 10. Foi divulgada em nota explicativa restrição sobre uso de itens materiais do ativo? } \\
\hline \multicolumn{3}{|l|}{$\begin{array}{l}\text { 11. Foram divulgadas em notas explicativas as cláusulas e condições contratuais específicas ou não usuais } \\
\text { quando relacionadas a itens materiais do balanço patrimonial e da demonstração do resultado? }\end{array}$} \\
\hline \multicolumn{3}{|l|}{$\begin{array}{l}\text { 12. Foram divulgados, em nota explicativa, a natureza, o momento e as incertezas relacionadas a } \\
\text { obrigações, direitos e arranjos contratuais cujos valores a se realizar são matérias? }\end{array}$} \\
\hline \multicolumn{3}{|l|}{$\begin{array}{l}\text { 13. Foi divulgado em nota explicativa o risco significativo de crédito associado a um elemento material } \\
\text { do balanço patrimonial? }\end{array}$} \\
\hline \multicolumn{2}{|l|}{$\begin{array}{l}\text { 14. Para exposição material a risco de crédito, foi divulgado em nota explicativa o montante que melhor } \\
\text { representa sua exposição máxima ao risco de crédito ao término do período de reporte? }\end{array}$} & \\
\hline \multicolumn{3}{|l|}{$\begin{array}{l}\text { 15. Para exposição material a risco de liquidez, foi divulgada em nota explicativa uma análise dos } \\
\text { vencimentos para passivos financeiros não derivativos e instrumentos financeiros derivativos os quais } \\
\text { demonstrem os vencimentos contratuais? }\end{array}$} \\
\hline \multicolumn{3}{|l|}{$\begin{array}{l}\text { 16. Para exposição material a risco de mercado, foi divulgada em nota explicativa, para cada tipo de risco } \\
\text { de mercado, uma análise de sensibilidade à qual a entidade está exposta ao fim do período contábil, } \\
\text { mostrando como o resultado e o patrimônio líquido seriam afetados pelas mudanças diante do risco } \\
\text { relevante variável que seja razoavelmente possível naquela data? }\end{array}$} \\
\hline $\begin{array}{l}\text { 17. Quando divulgada a análise de sensibilidade, foram apresentados: } \\
\text { - os métodos e os pressupostos utilizados na elaboração e análise de sensibilidade; e } \\
\text { - alterações do período anterior nos métodos e pressupostos utilizados, e a razão para tais } \\
\text { alterações? }\end{array}$ & & \\
\hline
\end{tabular}

